\title{
Movilidad habitual y concentración territorial de la población inmigrante: el caso de la Región Metropolitana de Barcelona ${ }^{1}$
}

Jordi Bayona-i-Carrasco. Centre d'Estudis Demogràfics (CERCA) y Universitat de Barcelona, Barcelona, España.

Marc Ajenjo. Universitat Autònoma de Barcelona y Centre d'Estudis Demogràfics (CERCA), Barcelona, España.

RESUMEN | La reciente llegada de miles de inmigrantes extranjeros ha modificado el mercado laboral de la Región Metropolitana de Barcelona. Entre otros múltiples aspectos, se han observado cambios en las pautas de movilidad habitual, concretamente en los desplazamientos entre el lugar de residencia y el de trabajo. Primero se estudian las características más importantes de esta movilidad para la población inmigrante desde un punto de vista descriptivo, para posteriormente analizar el efecto que tiene sobre ella la distribución territorial, y en particular la concentración residencial. Los resultados indican un mayor tiempo de desplazamiento y una mayor utilización del transporte público por parte de los inmigrantes, junto con una menor predisposición a trabajar fuera del lugar de residencia, que afecta en mayor medida a las mujeres. El efecto de la concentración sobre la movilidad, medida a través de los que cambian de municipio, es significativo, aunque más que la concentración en sí misma, será la localización de esta concentración la que marcará los resultados.

PALABRAS CLAVE | migración, movilidad, concentración espacial.

ABSTRACT | The recent arrival of thousands of foreign immigrants has modified the labor market of the Metropolitan Region of Barcelona. This paper studies immigrant commuting behavior, especially those displacements produced between workplace and residence. Commuting characteristics will first be analyzed from a descriptive perspective, to then focus on the effects of territorial distribution over mobility. Results show that immigrants need more time for their displacements, and a greater intensity in public transport use. At the same time, they tend to work less outside their municipality of residence. If analyzed by gender, these patterns particularly affect women. Additionally, a clear concentration effect is also noticed, reinforced by location: A metropolitan center effect is observed, while peripheries penalize daily mobility.

KEYWORDS | migration, mobility, spatial concentration.

Recibido el 16 de mayo de 2017, aprobado el 10 de septiembre de 2017

E-mails: J. Bayona: jbayona@ced.uab.es|M. Ajenjo: majenjo@ced.uab.es

1 Este trabajo forma parte del proyecto de $\mathrm{I}+\mathrm{D}+\mathrm{I}$ "Diversidad, segregación y vulnerabilidad, análisis sociodemográfico” (CSO2014-54059-R), dirigido por el Dr. Andreu Domingo y financiado por el Ministerio de Economía y Competitividad. 


\section{Introducción}

El estudio de la distribución territorial y de las pautas de segregación residencial de la población inmigrante -o extranjera, según el caso- se ha realizado, mayoritariamente, desde la perspectiva de la localización del lugar de residencia de los individuos. Sin embargo, existen otros ámbitos de la vida diaria -lo que habitualmente se denomina como "espacio de vida" (Courgeau, 1988; Mendizábal ,1991)-, como pueden ser la escuela (para los menores), el lugar de trabajo, el lugar donde se realizan las compras o bien los espacios de ocio, que complementan la visión puramente residencial. Estos ámbitos configuran una parte muy importante de la vida de los individuos, e incluso les podríamos atribuir una mayor transcendencia que el propio lugar de residencia si nos referimos al desarrollo del proceso de integración, considerando el papel primordial que estos espacios tienen en la posibilidad de interacción con la sociedad de acogida. Es desde esta perspectiva que en este trabajo se plantea el análisis de las pautas de movilidad habitual y, en particular, de los desplazamientos entre lugar de trabajo y lugar de residencia de la población inmigrante. Además de ser, por sí mismo, un aspecto de fuerte importancia en la vida diaria de los inmigrantes, la movilidad habitual muestra la relación existente entre lugar de residencia y lugar de trabajo. Una mayor segregación y concentración residenciales, por ejemplo, podrían estar en el origen de una mayor segregación laboral, relación que se visualizaría en las características de la movilidad diaria.

En este marco, el objetivo del artículo es doble. Por un lado, describir de manera pormenorizada el comportamiento de la población inmigrante en la movilidad habitual por razones laborales, identificando las divergencias existentes por sexo y origen, así como su impacto sobre la movilidad global; y, por el otro, estudiar los efectos de la localización territorial y, en especial, de la concentración residencial sobre las pautas de movilidad habitual de los diferentes colectivos de inmigrantes.

Para el estudio de las pautas recientes de movilidad habitual se utilizan los microdatos del último Censo de población y vivienda del año 2011 en Espańa, y se analizan las características de la movilidad por razón de trabajo de los inmigrantes ocupados que residen en la ciudad de Barcelona y en su Región Metropolitana $(\mathrm{RMB})$. Se diferencia a dicha población según su lugar de origen, a partir de una agrupación continental (resto de Europa, África, Latinoamérica y Asia). Se analiza la movilidad diaria de los distintos grupos así definidos en función de las características sociodemográficas de los individuos que los componen y de su lugar de residencia, definiendo las unidades espaciales de referencia a partir de los niveles de concentración de la población inmigrante que presentan.

Las principales líneas de investigación sobre el comportamiento de la población inmigrante en relación con la movilidad habitual inciden en que la movilidad viene condicionada por el lugar de residencia, definido este a partir de dos vectores: (i) el emplazamiento dentro de la estructura morfológica metropolitana, es decir, si se reside en el centro de la ciudad, en barrios periféricos o en municipios suburbanos; y (ii) los niveles de concentración residencial. Ambas características pueden incidir en las peculiaridades de la ocupación y, por ende, en la movilidad habitual asociada. La hipótesis que planteamos es que existe un efecto de la concentración territorial 
sobre la movilidad, esperándose una menor movilidad de los residentes en espacios de concentración debido a que esta se acompaña de la existencia de negocios étnicos y una mayor posibilidad de trabajar en el mismo entorno de residencia.

Por otro lado, se considera que las características de la movilidad resultante pueden informar de una mayor vulnerabilidad de la población inmigrante y ser reflejo de una disfunción entre localización residencial y laboral, con un mayor coste personal de acceso al mercado laboral entre los inmigrantes, que se manifiesta en la movilidad habitual y en sus características.

\section{Estado de la cuestión y marco teórico: la relación entre inmigración, territorio y movilidad diaria}

La población extranjera e inmigrante en la Región Metropolitana de Barcelona A raíz del boom inmigratorio internacional experimentado por el conjunto de España a inicios del siglo XxI, la población inmigrante en la RMB conoció súbitos incrementos durante un decenio, hasta alcanzar en la actualidad, y con datos del Padrón Continuo de Población de 2015, valores del 16,9\% de la población y 847.000 residentes, uno de cada seis habitantes metropolitanos, después de conocer un ligero descenso desde los máximos de 2011, cuando representaban el 17,3\% de la población. Debido al particular perfil sociodemográfico de los inmigrantes, la proporción que representan en algunos grupos de edad es incluso mayor, como es el caso de la población en edades activas, donde hasta el 22,5\% de los presentes es de origen extranjero. En general, se trata de valores que se sitúan bastante por encima de los conocidos en el conjunto de Espańa por la atracción que experimentan los inmigrantes hacia las mayores áreas metropolitanas del país. Esta mayor representación se encuentra sobredimensionada en algunos colectivos, como los latinoamericanos y asiáticos, más presentes en las áreas urbanas por su mayor dedicación laboral al sector terciario. Un ejemplo de ello es la composición actual por nacionalidades de los inmigrantes de la RMB, donde casi la mitad son latinoamericanos $(47,2 \%)$, una quinta parte europeos (21,7\%), un 17,2\% africanos y el 13,7\% restante, asiáticos.

Con estas cifras, huelga decir que la llegada de inmigrantes internacionales ha representado un cambio muy importante en la dinámica demográfica de la RMB, y también en su mercado laboral. Además, otras dinámicas de alta intensidad se han producido al mismo tiempo en el ámbito metropolitano. Entre las más importantes se encuentra la continua dispersión de la población desde los espacios centrales y densificados hacia las periferias suburbanas (Bayona \& Pujadas, 2014; Pujadas, 2009); y de forma más reciente, de la actividad económica y de los lugares de trabajo (Alberich, 2010; Miralles-Guash, 2011), contrarrestada esta última por la concentración en los centros de las actividades de alto valor añadido relacionadas con la sociedad de la información (Marmolejo \& Roca-Cladera, 2008), en un entorno global donde crece el sector servicios en detrimento de la industria y la construcción. El incremento de la movilidad habitual será uno de los principales resultados de estas dinámicas metropolitanas recientes (Ajenjo, 2005), de forma similar a lo observado en otras metrópolis españolas, como Madrid (García Palomares \& Gutiérrez Puebla, 2007). Por otro lado, desde 2008 se empiezan a notar los efectos de la 
crisis económica, especialmente en las altas tasas de desocupación de la población inmigrante, efectos que, en cambio, son más difíciles de observar en la comparación entre los datos de 2001 y 2011.

\section{Sobre la segregación y la concentración de la población inmigrante}

La mayor parte de estudios sobre segregación consideran la perspectiva residencial, es decir, la diferenciación entre grupos de población en función de su lugar de residencia. No obstante, son crecientes los trabajos que examinan otros ámbitos de la vida diaria, preferentemente la escuela o el mundo laboral (la segregación escolar y la segregación laboral, respectivamente). Mientras que la segregación escolar se produciría en valores más intensos que su contraparte residencial (Gramberg, 1998 o Schindler, 2007), en la segregación laboral normalmente los valores serían menores (Marcińczak, Tammaru, Strömgren \& Lindgren, 2015), aunque evidentemente trabajar en un mismo entorno no tiene el mismo significado que residir en un mismo barrio.

No en todas las situaciones se reproduce esta menor segregación laboral. Es el caso de los inmigrantes recién llegados, por ejemplo, entre los que se identifican niveles de segregación laborales más elevados (Tammaru, Strömgren, van Ham \& Danzer, 2015), relacionados con el peso de las redes migratorias en proporcionar un primer empleo. Esta segregación se reduciría con el paso de los años. También la segregación laboral se encontraría directamente relacionada con el nivel de estudios, de forma que la segregación laboral sería mayor para aquellos con menores niveles de instrucción (Glitz, 2014).

Desde otra perspectiva, se centra la atención en la relación entre segregación residencial y segregación laboral. Se identifica una clara correlación entre niveles altos de ambas situaciones (Ellis, Wright \& Parks, 2004; Marcińczak et al., 2015), que afectarían de diferente forma a hombres y mujeres. Entre los primeros, el descenso de los niveles de segregación residencial no conllevaría un descenso similar en la segregación laboral, que sí ocurriría entre las mujeres (Tammaru et al., 2015).

En el caso de Espańa, una menor segregación laboral no siempre es posible: los muy bajos niveles de segregación residencial de algunos colectivos, como el latinoamericano, lo dificultan. Por ejemplo, Sabater y Galeano (2015) encuentran dinámicas divergentes, con una segregación residencial descendiente al mismo tiempo que aumenta la segregación laboral, especialmente para las mujeres, y donde la integración residencial de los latinoamericanos (por los muy bajos niveles de segregación) se produce a costa de una fuerte desventaja laboral.

En el caso de la RMB, la llegada e inserción de inmigrantes internacionales se ha producido con unos niveles de segregación residencial moderados e incluso bajos, si exceptuamos casos concretos, como los de los colectivos pakistaní, indio o filipino, con fuerte concentración en los barrios históricos de la ciudad central (Bayona \& López-Gay, 2011; García-Almirall, Fullaondo \& Frizzera, 2008; Martori \& Apparicio, 2011) y de sus periferias inmediatas (Galeano \& Bayona, 2015). En los años del boom migratorio, Barcelona experimentó un crecimiento mayor de inmigrantes en comparación con su entorno metropolitano, que se contrarresta posteriormente con una elevada intensidad de los procesos de desconcentración vía movilidad residencial (Sabater, Bayona \& Domingo, 2012). 
En cuanto a la concentración, es especialmente el centro histórico de la ciudad de Barcelona donde se vienen observando los valores más elevados de inmigrantes extranjeros, aunque recientemente han aparecido nuevos espacios de concentración en las periferias circundantes. Según algunas aproximaciones, una de las máximas expresiones de la concentración sería el enclave étnico, definido a partir de la propia concentración de un grupo determinado. Según la clasificación utilizada por Johnston, Forrest y Poulsen (2002), el número de enclaves existentes en 2011 en la RMB era de 31 a escala de sección censal (Galeano, Sabater \& Domingo, 2014), la mayoría de ellos en la ciudad de Barcelona y en municipios de la primera corona metropolitana. En 2013, solo en el Área Metropolitana de Barcelona² ya se encontraban 31 secciones con estas características (Galeano \& Bayona, 2015), con un incremento de tres secciones en relación con el recuento precedente. Existen otras formas de medir la concentración. Yang-Liu (2009), por ejemplo, define las áreas de concentración a partir de un cociente de localización superior a 2 (es decir, que dobla la presencia en el resto de la metrópolis), mientras que Musterd (2006) utiliza el peso promedio de un grupo sobre el total de la población más cuatro desviaciones típicas. En general, cualquier aproximación a la concentración utiliza un umbral determinado para definirla.

Los trabajos recientes sobre concentración residencial de inmigrantes se decantan hacia lo que es conocido como "efecto barrio" o neighbourhood effects (van Ham, Manley, Bailey, Simpson \& Maclennan, 2012), y que se resume en la posibilidad de que la composición social y económica del entorno en que uno viva tenga o no un efecto - positivo o negativo- sobre sus residentes, ya sea en el plano económico, educativo o familiar. En el caso de los inmigrantes extranjeros, la existencia de este posible efecto barrio significaría, además, la estigmatización de sus lugares de residencia, que conlleva la aparición de menores oportunidades tanto en el campo educativo como en el laboral.

\section{Sobre la movilidad diaria de los inmigrantes}

Varios mecanismos son identificados como contraproducentes en la movilidad habitual de la población inmigrante, y que varían en función de la segregación residencial existente o de la concentración territorial y del empleo (Strömgren et al., 2014). En primer lugar, se identifica lo que se denomina como "efectos de proximidad", referidos a aquellos basados en la importancia de la distancia entre lugar de residencia y lugar de trabajo. Para algunos colectivos extranjeros, y debido a la propia localización residencial, se observa un aumento de los costes de la movilidad (económicos o de tiempo), con el resultado de la no aceptación de nuevas opciones laborales al ser los costes del commuting demasiado elevados, lo que en definitiva acaba por reducir su inserción laboral, con el consiguiente aumento de las tasas de paro. De forma similar, se identifican ciertas prácticas entre los empleadores, entre ellas la preferencia expresada por contar con trabajadores de mayor proximidad (lo que a priori generaría menor absentismo laboral y menores retrasos), con el resultado de menores oportunidades laborales para el grupo segregado.

2 En este caso se trata de los 36 municipios centrales de la RMB, con 628.000 inmigrantes en 3,239 millones de residentes. 
Desde la perspectiva contraria, existe un efecto positivo sobre la empleabilidad a partir de los llamados comercios étnicos, más fácilmente localizados en zonas de concentración y que se nutren preferentemente de empleados de la misma zona residencial (y origen). En este caso, la proximidad y la concentración suponen el criterio fundamental para sustentar las redes sociales que los mantienen (Moreras, 2002), existiendo, además, el efecto de la red de contactos para encontrar, en una economía informal, un lugar de trabajo, a pesar de que estos recursos se encuentren asociados, especialmente en un primer trabajo, a una movilidad laboral descendente (Vono \& Vidal, 2012).

Como grupo vulnerable, los inmigrantes dependen en alto grado de las características del transporte público metropolitano. Este deviene un importante instrumento de integración y cohesión social, como indica Avellaneda (2008) para el caso de Lima, o Rodríguez (2008) para cuatro metrópolis de Latinoamérica. Tal situación se ve reforzada por el emplazamiento de su lugar de residencia, en cuanto es cada vez más habitual que la población inmigrante se encuentre residiendo en zonas periféricas (Alba, Logan, Stults, Marzan \& Zhang,1999), a semejanza de las poblaciones con menores recursos económicos, como el mismo caso de estudio, la ciudad de Barcelona (Bayona \& López-Gay, 2011). Esta localización se relaciona con los menores costes residenciales de viviendas con estándares habitacionales más bajos y situadas lejos del centro de la ciudad, en una localización residencial que -en el caso de la RMB- recuerda la establecida por antiguas corrientes migratorias. Esto puede conllevar un mayor uso del transporte público para acceder a sus lugares de trabajo, intensificando la importancia del coste del mismo en la localización. Entonces, residir en espacios cercanos a los principales corredores ferroviarios resulta determinante y guía la ubicación territorial.

En cuanto a las características de la movilidad, el tiempo empleado en los viajes al lugar de trabajo ha sido utilizado por algunos autores (Blázquez, Llano \& Moral, 2010) como un buen indicador para comprobar la teoría del spatial mismatch (Painter, Liu \& Duan, 2007), según la cual la creciente diferenciación entre una residencia localizada en su mayoría en los centros de las grandes urbes, y unos lugares de trabajo que se desplazan continuamente hacia el extrarradio, provoca una situación de desventaja laboral para los extranjeros, resultando en un menor acceso a la ocupación, el consiguiente aumento del paro y, finalmente, un mayor tiempo empleado entre desplazamiento y trabajo entre los ocupados. La única contrapartida a esta situación es la mayor capacidad de adaptación de la población inmigrante, debido a una mayor movilidad residencial. La distancia recorrida, en cambio, acostumbra a ser menor, aunque los años de residencia en el país de recepción actúan provocando su paulatina desaparición (Newbold, Scott \& Burke, 2015).

Un segundo aspecto considerado es la diferencia en la movilidad diaria laboral de los inmigrantes en función del sexo, caracterizándose las mujeres por ejercer ocupaciones laborales en lugares más próximos a la residencia, por sus mayores responsabilidades en el hogar. Esto comporta que la segregación residencial y la concentración les puedan afectar más, con un descenso de la oferta disponible, resultando en una creciente segregación laboral. Adicionalmente, se indica un efecto negativo de la concentración sobre la eficiencia en la búsqueda de trabajo, debido 
a que la red de contactos, a pesar de ser muy densa, se encuentra muy localizada territorialmente, lo que representa la limitación de la búsqueda de trabajo al propio barrio de residencia.

Por otro lado, en un contexto de movilidad creciente y de dispersión de la actividad económica a escala metropolitana, disponer de transporte privado resulta clave para acceder al mercado laboral, en un contexto además caracterizado por el reciente crecimiento de la movilidad en transporte privado (Gutiérrez-Puebla \& García-Palomares, 2005). Cebollada (2009) indica cómo los inmigrantes, por no tener transporte privado, junto con los jóvenes y las mujeres, son los que se encuentran más veces excluidos del mercado laboral en la Región Metropolitana de Barcelona. En cambio, el impacto de la crisis económica también incide en las pautas de movilidad, pudiendo haber hecho ajustar el costo y las características del transporte entre las familias más afectadas por la crisis, entre las que se encuentran los inmigrantes (Marquet \& Miralles-Guash, 2017).

\section{Datos estadísticos y metodología empleada}

La relación entre lugar de residencia, lugar de trabajo y movilidad habitual se estudia bajo una perspectiva metropolitana, ya que es en este ámbito donde se localiza mayoritariamente el mercado laboral de los individuos. En nuestro caso, se utiliza la Región Metropolitana de Barcelona (RмB), que cuenta con 164 municipios agrupados en siete comarcas y en unos $3.200 \mathrm{~km}^{2}$, con 5,024 millones de residentes en 2015. Es uno de los siete ámbitos considerados en el Pla Territorial General de Catalunya, con una definición que se remonta a la década de los sesenta (Esteban, 2003), y que se configura en la mayoría de estudios con perspectiva metropolitana como la unidad de análisis preferente.

Los datos empleados provienen del Censo de población de 2011. Este, a diferencia del censo precedente, tiene carácter muestral, con lo cual no se dispone de todas las características sociodemográficas de los individuos por sección censal. La mayor unidad de desagregación de los microdatos disponible debe superar, por razones de secreto estadístico y de fiabilidad de los mismos, los 20.000 residentes. Con esta limitación, se subdivide la ciudad de Barcelona y el resto de municipios metropolitanos en unidades de un mínimo de 20.000 individuos, resultando un total de 190 subunidades en el conjunto de la RMB, 57 de ellas ubicadas en la ciudad central. En la medida en que ha sido posible, se ha mantenido la agrupación de unidades administrativas preexistentes (barrios o Áreas Estadísticas Básicas [AEB], en el caso de la ciudad de Barcelona, o comarcas a nivel supramunicipal). ${ }^{3}$ De la misma manera, los municipios menores a 20.000 residentes se han agrupado, respetando, siempre que ha sido posible, el límite comarcal.

Para la identificación de la población objeto de estudio se ha utilizado el criterio del país de nacimiento y no el de la nacionalidad. Esta decisión conlleva el aumento del tamaño de la muestra, teniendo más sentido algunas subdivisiones de variables 
empleadas. Al mismo tiempo, esta elección es cada vez más necesaria para analizar algunos grupos de inmigrantes, sea el caso de los latinoamericanos, donde el acceso a la nacionalidad española ha sido durante los últimos años muy importante. Se han agrupado los inmigrantes en cuatro grandes grupos: resto de europeos, africanos, latinoamericanos y asiáticos.

En el estudio de las características de la movilidad por razones laborales se trabaja con toda la población residente en la RMB, con independencia de dónde se encuentre su lugar de trabajo. Las tres principales variables recogidas por el censo de 2011 sobre movilidad diaria y que se explotan en este trabajo son el municipio de trabajo, el medio de transporte y el tiempo empleado en la movilidad.

Para aproximarnos al estudio de la segregación y concentración de la población extranjera se utilizan diversos indicadores habituales en la literatura científica, como son los índices de disimilaridad (Duncan \& Duncan, 1955) y de segregación (Gorard \& Taylor, 2002). El índice de disimilaridad (D) y el de segregación (Is) responden a las siguientes formulaciones:

Donde la $\mathrm{x}_{\mathrm{i}}$ se refiere a la población de un grupo $\mathrm{X}$ en la unidad territorial $i, \mathrm{X}$ es la población total del grupo en el conjunto del territorio analizado, $\mathrm{y}_{\mathrm{i}}$ es la población nacida en Espańa en la unidad territorial (sección censal) i, e Y la población total nacida en Espańa.

$$
D=\frac{1}{2} \sum_{i=1}^{n}\left|\frac{x_{i}}{X}-\frac{y_{i}}{Y}\right| \quad I S=\frac{1}{2} \sum_{i=1}^{n}\left|\frac{X_{i}}{X}-\frac{t_{i}-x_{i}}{T-X}\right|
$$

En el segundo caso, t es el conjunto de población de la unidad y $\mathrm{T}$ del municipio. Estos indicadores varían entre los valores de 0 y 1 -o entre 0 y 100, multiplicados por cien, como utilizamos aquí para mejorar la comprensión-, donde el valor 0 indica que todos los miembros del colectivo se reparten homogéneamente por el territorio; mientras que el valor 1 significa que todos los integrantes del colectivo se encuentran concentrados en unidades territoriales donde no hay presencia de autóctonos. Estos indicadores se emplean con las 190 subunidades con las que subdividimos la RMB, y se utilizan para proporcionar datos comparativos con otros trabajos que emplean otro tipo de delimitaciones.

En cuanto a la definición de la concentración, se ha utilizado para cada uno de los cuatro grupos de inmigrantes categorías propias, a partir del cálculo de su media (es decir, su peso sobre el total de población), más una medida de dispersión, la desviación típica, dando lugar a cuatro categorías. La primera por debajo de la media $(<0)$; la segunda entre la media y una desviación típica $(0-1)$; la tercera entre la media más una desviación y la media más dos desviaciones (1-2); y una última por encima de las dos desviaciones típicas. La representación cartográfica de los espacios de concentración de cada grupo se encuentra en la figura 2.

Con el fin de explicar la incidencia de la concentración en la movilidad habitual por trabajo, se compara la movilidad de cada agregado continental en los distintos niveles de concentración con la de los españoles residentes en estas mismas zonas. Para ello, para cada grupo continental se ha llevado a cabo una regresión logística donde, además de las variables explicativas (agregado continental y concentración), 
se han introducido, como variables de control, el sexo, la edad, el nivel de estudios y el sector de actividad. Así, cada una de las relaciones de odds muestra la diferencia neta entre cada grupo de inmigrantes definidos (por su origen continental) y los autóctonos. ${ }^{4}$

\section{Concentración y segregación residencial de la población inmigrante metropolitana}

La población nacida en el extranjero, según el censo de 2011, representa el 14,8\% de los casi cinco millones de residentes presentes en la RMB, sumando 737.818 personas. De estos, en un $51,1 \%$ son latinoamericanos, $21,6 \%$ europeos, $17,7 \%$ africanos, $8,5 \%$ asiáticos y el 1,1\% restante proviene de Norteamérica u Oceanía. En el conjunto de inmigrantes existe un cierto equilibrio entre sexos (el 51\% son hombres), mientras que, por continentes, los africanos $(59,8 \%)$ y asiáticos $(56 \%)$ se encuentran masculinizados, al tiempo que los latinoamericanos están ligeramente feminizados (47,3\% de hombres).

FIgURA I | Proporción de inmigrantes sobre la población total, RMB, 2011



FUENTE MiCRodatos DEL CENSO DE POBLACión DE 20 I I, CON DATOS DEL INE

En la figura 7 se han convertido las odds a probabilidades, de modo que se muestra directamente la probabilidad de desplazarse a trabajar a otro municipio a igualdad de sexo, edad, nivel de estudios y sector de actividad. Por otro lado, y debido al reducido tamaño muestral, no se considera el grupo formado por los nacidos en Norteamérica ni en Oceanía. 
FIGURA 2 Localización territorial de los espacios de concentración según la agrupación continental

\section{Europeos}

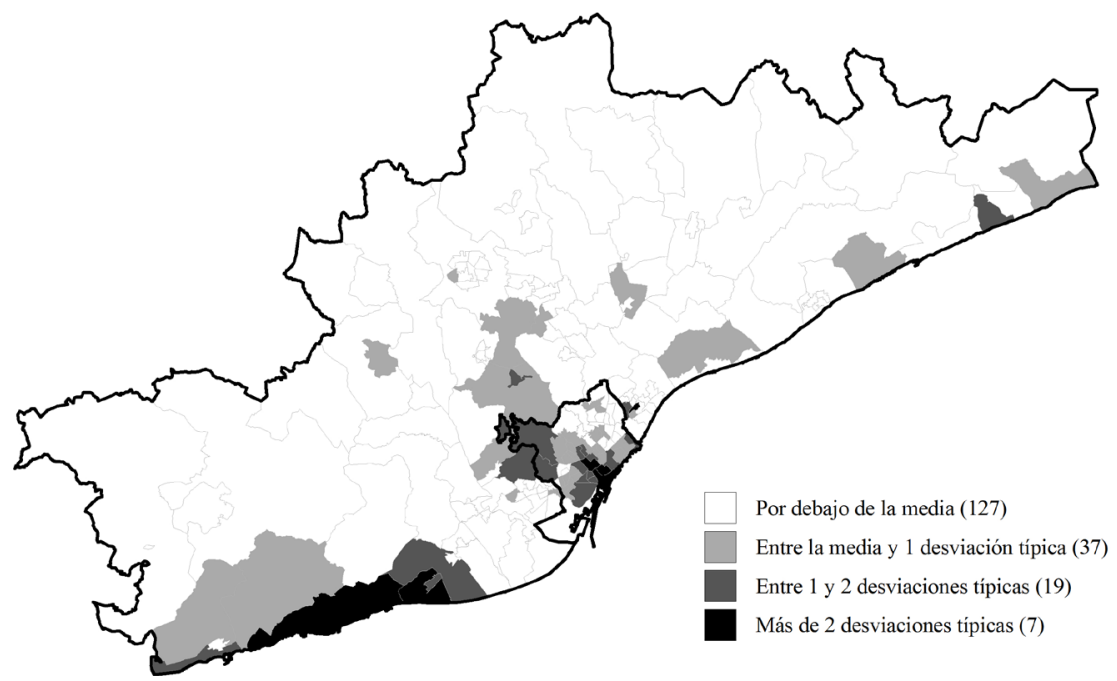

\section{Africanos}

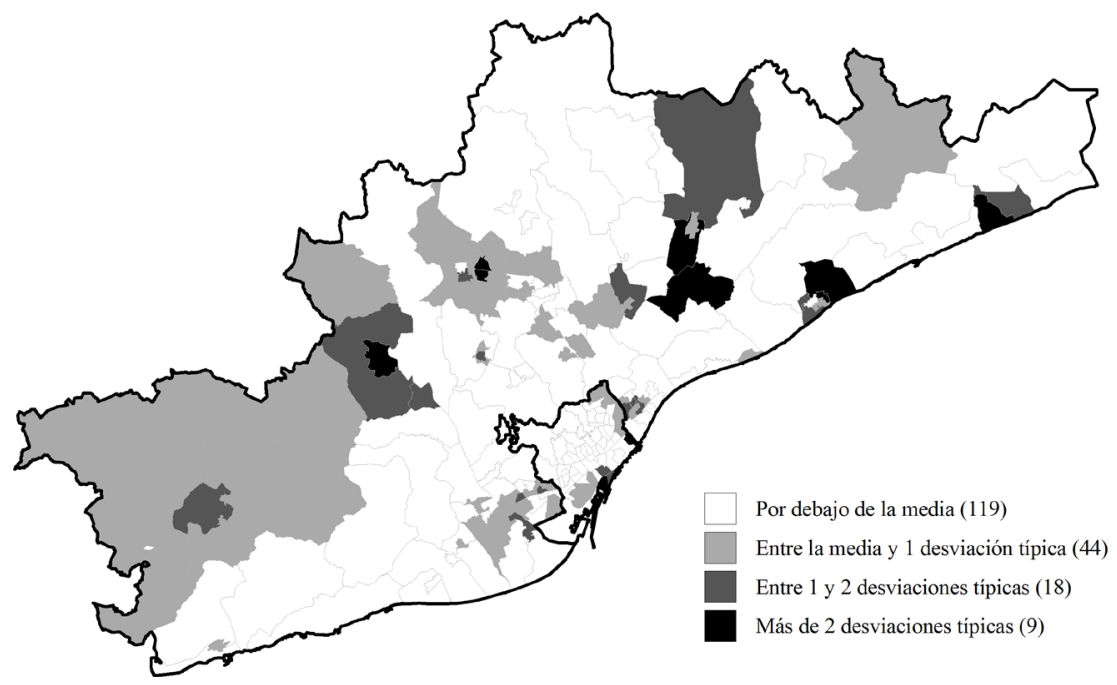




\section{Latinoamericanos}

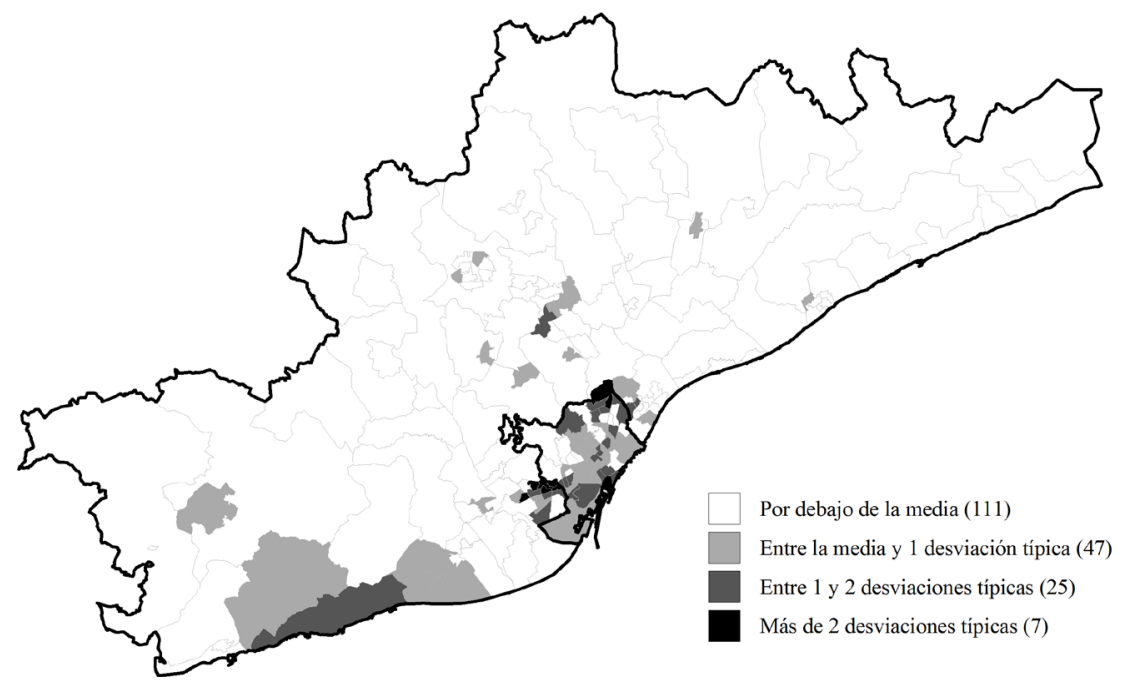

\section{Asiáticos}

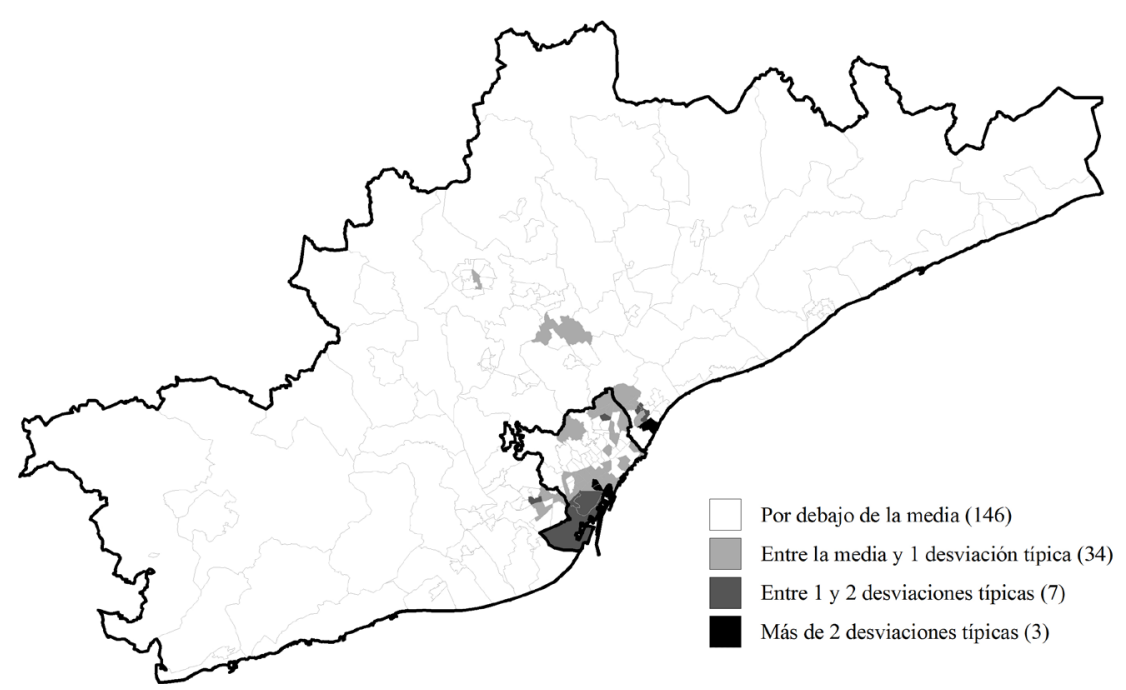

FUENTE ELABORACIÓN PROPIA CON BASE ENMICRODATOS DEL CENSO DE POBLACIÓN DE 20 I I

La distribución territorial de la población inmigrante es desigual, con zonas metropolitanas donde su peso es poco importante (un mínimo del 4,7\% en un área de la periferia), hasta incluso superar más de la mitad de los residentes (el 50,6\% en el centro de Barcelona). En 33 de las 190 unidades en las que se subdivide la RMB se supera el umbral del $20 \%$ de la población (véase figura 1), lo que indica una 
cierta concentración relativa de inmigrantes, situación que afecta sobremanera a los asiáticos, ya que el $57,6 \%$ de los residentes de este colectivo vive en estos espacios, con valores cercanos al 30\% entre el resto de extranjeros. En su localización, estas áreas se sitúan mayoritariamente en la misma ciudad de Barcelona (en el centro de la ciudad y en el noreste, alrededor del distrito de Nou Barris) y en los municipios vecinos de l'Hospitalet de Llobregat, por un lado, y de Santa Coloma de Gramenet y Badalona por el otro. ${ }^{5}$ En la periferia, además, encontramos espacios con concentración de inmigrantes en ciudades medias, como Rubí, Terrassa, Sabadell y Mataró, y en zonas litorales turísticas, como el área comprendida entre los municipios de Castelldefels y Sitges al sur, o el municipio de Calella en el norte.

Los espacios de concentración de cada uno de los cuatro grandes grupos, calculados como se indica en la metodología, presentan divergencias importantes en su localización, coincidiendo únicamente en una mayor representación de todos ellos en el barrio del Raval (figura 2), el cual juega un importante rol de puerta de entrada de los procesos migratorios a la ciudad. En el primer caso cartografiado, el del resto de europeos, se identifican 63 zonas por encima de la media; de ellas, las mayores concentraciones se producen en el distrito de Ciutat Vella en Barcelona, en el litoral sur de la ciudad (Sitges-Castelldefels) y en dirección a Sant Cugat del Vallès, reproduciendo las líneas de dispersión de las clases sociales más acomodadas de la ciudad (Rubiales, Bayona \& Pujadas, 2012).

Para el colectivo africano, 71 son las zonas de concentración, que se caracterizan por su dispersión metropolitana. Mataró, Terrassa, Montornès del Vallès o Martorell acogen concentraciones importantes en ciudades de una segunda corona metropolitana, que se suman a pequeñas concentraciones observadas en el distrito de Ciutat Vella y en ambos extremos de la ciudad central, en l'Hospitalet de Llobregat y Santa Coloma de Gramenet. En el caso de los latinoamericanos, son 79 las zonas identificadas por encima de la media, destacando su concentración en la ciudad de Barcelona y en el área de l'Hospitalet de Llobregat, donde junto con zonas de Esplugues de Llobregat y Cornellà de Llobregat se conforma un área de importante concentración, con niveles que también se alcanzan en el distrito de Nou Barris, en el noreste de la ciudad central. En los asiáticos, en cambio, el número de zonas identificadas es menor, solo 44, aunque esto es producto de sus elevados niveles de concentración. Esta se produce en casi su totalidad en el centro metropolitano y los municipios colindantes de l'Hospitalet de Llobregat, Santa Coloma de Gramenet y Badalona.

La composición por orígenes de estos espacios se muestra en la tabla 1, donde se observa cómo en los cuatro casos la concentración se asocia a porcentajes más elevados de inmigrantes, con valores máximos entre los asiáticos. Los latinoamericanos son los que comparten en mayor medida estos espacios con autóctonos (1,7 millones de españoles), mientras que el caso opuesto es el de los asiáticos (no se alcanzan las 900.000 personas). En los máximos niveles de concentración se encontraría desde un porcentaje mínimo de los latinoamericanos (el 9,7\%) al máximo de los asiáticos (el 26,8\%). Por otro lado, los europeos son los que más diversidad 
experimentan, ya que únicamente representan el 39,9\% de los inmigrantes en las zonas de mayor concentración, mientras que la mayor especialización se produce entre los latinoamericanos, que constituyen el $71,2 \%$ de los inmigrantes en los espacios de concentración.

TABLA I | Características de la población en las áreas de concentración, según la agrupación continental

\begin{tabular}{|c|c|c|c|c|c|c|c|c|}
\hline EUROPEOS & ÁREAS & ESPAÑOLES & $\begin{array}{c}\text { INMI- } \\
\text { GRANTES }\end{array}$ & TOTAL & $\begin{array}{c}\% \\
\text { INMI- } \\
\text { GRANTES }\end{array}$ & EUROPEOS & $\begin{array}{c}\text { EUROPEOS } \\
\text { / TOTAL } \\
\text { POBLACIÓN }\end{array}$ & $\begin{array}{c}\text { EUROPEOS } \\
\text { / INMI- } \\
\text { GRANTES }\end{array}$ \\
\hline No concent. & 127 & 2.872 .561 & 418.579 & 3.291 .140 & 12,7 & 64.920 & 2,0 & 15,5 \\
\hline $\begin{array}{l}\text { Concent. } \\
\text { baja }\end{array}$ & 37 & 867.228 & 160.781 & 1.028 .009 & 15,6 & 43.122 & 4,2 & 26,8 \\
\hline $\begin{array}{l}\text { Concent. } \\
\text { media }\end{array}$ & 19 & 393.868 & 114.235 & 508.103 & 22,5 & 33.789 & 6,7 & 29,6 \\
\hline $\begin{array}{l}\text { Concent. } \\
\text { alta }\end{array}$ & 7 & 115.921 & 44.223 & 160.144 & 27,6 & 17.650 & 11,0 & 39,9 \\
\hline AFRICANOS & ÁREAS & ESPAÑOLES & $\begin{array}{c}\text { INMI- } \\
\text { GRANTES }\end{array}$ & TOTAL & $\begin{array}{c}\% \\
\text { INMI- } \\
\text { GRANTES }\end{array}$ & AFRICANOS & $\begin{array}{c}\text { AFRICANOS } \\
\text { / TOTAL } \\
\text { POBLACIÓN }\end{array}$ & $\begin{array}{c}\text { AFRICANOS } \\
\text { / INMI- } \\
\text { GRANTES }\end{array}$ \\
\hline No concent. & 119 & 2.749 .521 & 416.245 & 3.165 .766 & 13,1 & 34.685 & 1,1 & 8,3 \\
\hline $\begin{array}{l}\text { Concent. } \\
\text { baja }\end{array}$ & 44 & 951.807 & 193.277 & 1.145 .084 & 16,9 & 44.993 & 3,9 & 23,3 \\
\hline $\begin{array}{l}\text { Concent. } \\
\text { media }\end{array}$ & 18 & 391.778 & 91.004 & 482.782 & 18,8 & 30.615 & 6,3 & 33,6 \\
\hline $\begin{array}{l}\text { Concent. } \\
\text { alta }\end{array}$ & 9 & 156.472 & 37.292 & 193.764 & 19,2 & 20.511 & 10,6 & 55,0 \\
\hline $\begin{array}{l}\text { LATINO } \\
\text { AMERI- } \\
\text { CANOS }\end{array}$ & ÁREAS & ESPAÑOLES & $\begin{array}{c}\text { INMI- } \\
\text { GRANTES }\end{array}$ & TOTAL & $\begin{array}{c}\% \\
\text { INMI- } \\
\text { GRANTES }\end{array}$ & $\begin{array}{l}\text { LATINO } \\
\text { AMERI- } \\
\text { CANOS }\end{array}$ & $\begin{array}{l}\text { LAT./TOTAL } \\
\text { POBLACIÓN }\end{array}$ & $\begin{array}{l}\text { LAT./ INMI- } \\
\text { GRANTES }\end{array}$ \\
\hline No concent. & 111 & 2.541 .392 & 307.040 & 2.848 .432 & 10,8 & 136.347 & 4,8 & 44,4 \\
\hline $\begin{array}{l}\text { Concent. } \\
\text { baja }\end{array}$ & 47 & 1.083 .659 & 236.225 & 1.319 .884 & 17,9 & 121.043 & 9,2 & 51,2 \\
\hline $\begin{array}{l}\text { Concent. } \\
\text { media }\end{array}$ & 25 & 491.271 & 143.375 & 634.646 & 22,6 & 82.881 & 13,1 & 57,8 \\
\hline $\begin{array}{l}\text { Concent. } \\
\text { alta }\end{array}$ & 7 & 133.256 & 51.178 & 184.434 & 27,7 & 36.441 & 19,8 & 71,2 \\
\hline ASIÁtICOS & ÁREAS & ESPAÑOLES & $\begin{array}{c}\text { INMI- } \\
\text { GRANTES }\end{array}$ & TOTAL & $\begin{array}{c}\% \\
\text { INMI- } \\
\text { GRANTES }\end{array}$ & ASIÁTICOS & $\begin{array}{c}\text { ASIÁTICOS/ } \\
\text { TOTAL } \\
\text { POBLACIÓN }\end{array}$ & $\begin{array}{c}\text { ASIÁTICOS } \\
\text { / INMI- } \\
\text { GRANTES }\end{array}$ \\
\hline No concent. & 146 & 3.363 .744 & 482.012 & 3.845 .756 & 12,5 & 15.416 & 0,4 & 3,2 \\
\hline $\begin{array}{l}\text { Concent. } \\
\text { baja }\end{array}$ & 34 & 711.053 & 185.048 & 896.101 & 20,6 & 20.616 & 2,3 & 11,1 \\
\hline $\begin{array}{l}\text { Concent. } \\
\text { media }\end{array}$ & 7 & 137.393 & 42.180 & 179.573 & 23,5 & 9.993 & 5,6 & 23,7 \\
\hline $\begin{array}{l}\text { Concent. } \\
\text { alta }\end{array}$ & 3 & 37.388 & 28.578 & 65.966 & 43,3 & 16.887 & 25,6 & 59,1 \\
\hline
\end{tabular}

FUENTE ELABORACIÓN PROPIA CON BASE EN MICRODATOS DEL CENSO DE POBLACIÓN DE 2 OI I 
Finalmente, y utilizando las 190 unidades territoriales como referencia, se calculan los principales indicadores de segregación. En primer lugar, el índice de segregación (Is), con valores obtenidos -y su gradación entre orígenes- que no difieren mucho de los calculados utilizando otras escalas geográficas y oscilan entre el mínimo valor de los latinoamericanos (22,63 sobre 100), que indica su elevada dispersión en el territorio, al máximo de los asiáticos (53,28 sobre 100$)$, producto de su mayor concentración. Valores del 26,12 y del 38,02 se calculan para europeos y africanos, respectivamente. $\mathrm{Si}$, en cambio, se emplea el índice de disimilaridad (ID), que compara la distribución de dos grupos entre sí, los valores más bajos corresponden al binomio de europeos y latinoamericanos (26,85 sobre 100$)$, y el más alto, el que relaciona africanos con asiáticos $(62,80)$, que serían, por lo tanto, los dos grupos que menos territorio compartirían entre sí. Este valor refleja, en parte, la dicotomía existente entre el centro y la periferia en los espacios de concentración de ambos colectivos.

\section{Características de la movilidad habitual por motivos laborales entre la población inmigrante}

La movilidad habitual por motivos laborales solo se considera para la población inmigrante entre 16 y 64 años de edad que se encontraba ocupada en la fecha censal. Se trata, en este caso, de un conjunto de 315.735 inmigrantes, los cuales representan el 15,6\% de todos los ocupados metropolitanos. Entre ellos los latinoamericanos son mayoritarios (el 54,3\%), con un peso importante de los europeos $(25,8 \%)$, ambos por encima de su presencia entre el conjunto de la población, mientras que la proporción de africanos es inferior a la esperada $(10,3 \%)$ debido al mayor efecto del desempleo. ${ }^{6}$ Esto es lo que se representa en la figura 3, donde se observan las intensas consecuencias de la crisis económica sobre los inmigrantes, al presentar estos elevadas proporciones de desocupados entre la población activa. Esta situación afecta, en mayor medida que a otros colectivos, a los inmigrantes africanos, hasta el punto de que únicamente un 35,8\% de los hombres y un 19,3\% de las mujeres entre 16 y 64 años de edad se encuentran ocupados. En conjunto, hasta el 26,7\% de todos los parados metropolitanos son extranjeros, porcentaje que se sitúa muy por encima de su peso en la RMB. Al mismo tiempo, representan un $20,7 \%$ de la población entre 16 y 64 años inactiva, cifra que de forma análoga denota las dificultades para encontrar trabajo del colectivo inmigrante. Por otro lado, las mujeres asiáticas y africanas son las que registran mayores proporciones de inactividad; alrededor del doble del resto de agrupaciones continentales. Se diferencian entre ellas por el peso de la desocupación, muy elevado entre las africanas y el más reducido entre las asiáticas. La variabilidad en las características sociodemográficas existente dentro del conjunto asiático podría explicar esta paradoja, debido a que las situaciones de chinas, pakistaníes o filipinas, por citar los orígenes más numerosos, pueden diferir ostensiblemente. En cambio, el único grupo con mayor

6 La presencia de asiáticos entre los ocupados $(8,4 \%)$ es prácticamente la misma que en el conjunto de la población inmigrante $(8,5 \%)$. 
ocupación femenina que masculina es el latinoamericano. Esta situación refleja una mejor adaptación a la crisis económica de estas mujeres, las cuales se encuentran en mayor proporción que otros orígenes trabajando en el sector servicios, menos afectado por la crisis económica.

En cuanto a la movilidad, en primer lugar se analiza la variable del lugar de trabajo, fijando la atención en la proporción de trabajadores que deben desplazarse fuera de su municipio de residencia para trabajar. Esta es la situación de poco más de la mitad de los trabajadores (el 51,0\%), con una movilidad más elevada entre los que han nacido en España (52,5\%) que entre los inmigrantes (43,1\%), y entre los hombres $(56,2 \%)$ en relación con las mujeres $(45,3 \%)$. Esta mayor movilidad de los hombres se reproduce sea cual sea el origen continental (tabla 2). En comparación con los autóctonos, en todos los colectivos continentales se observa una menor movilidad, una situación mucho más acentuada entre los asiáticos. La excepción corresponde a los africanos, entre los cuales las diferencias con respecto de los autóctonos son poco importantes, ya sea por el menor peso de las mujeres entre los ocupados o por su lugar de residencia en la periferia.

FIGURA 3 | Relación con la actividad de la población por origen, 16-64 años, Región Metropolitana de Barcelona, 2011

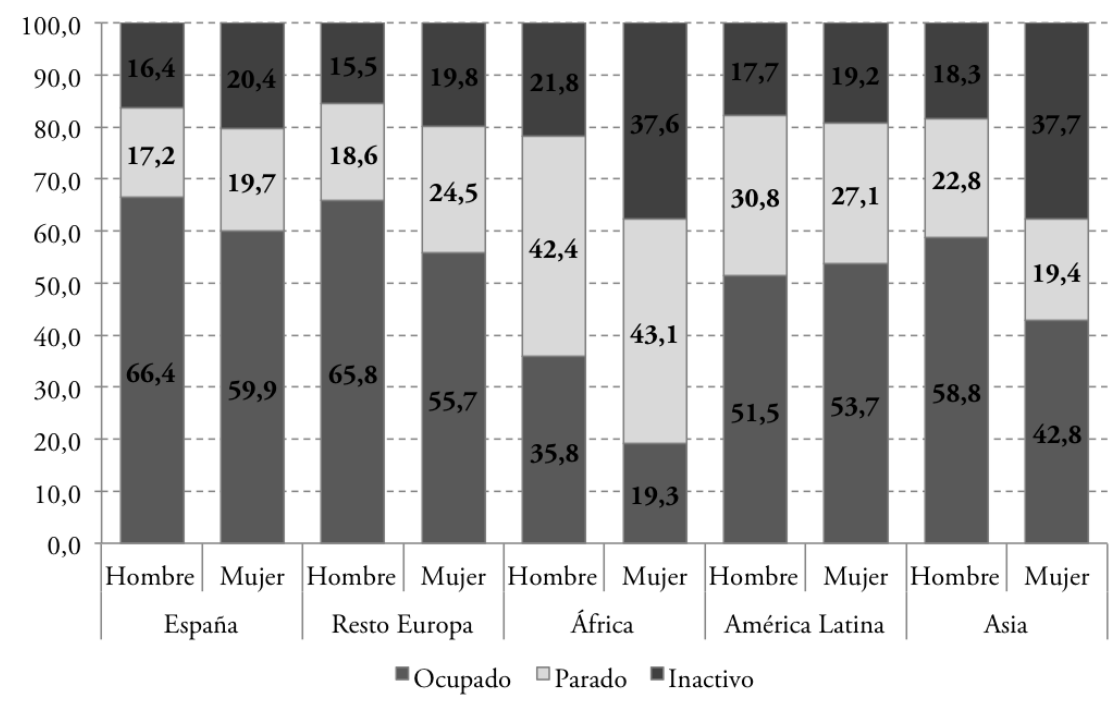

FUENTE MICRODATOS DEL CENSO DE POBLACIÓN DE 2 O I Y Y CON DATOS DEL INE 
TABla 2 Proporción de ocupados que trabajan fuera del municipio de residencia, por país de nacimiento y sexo, RMB, 2011 (porcentajes)

\begin{tabular}{|c|c|c|c|c|c|c|c|}
\hline & AUTóctonos & AFRICANOS & $\begin{array}{c}\text { LATINO- } \\
\text { AMERICANOS }\end{array}$ & ASIÁtICOS & EUROPEOS & $\begin{array}{c}\text { TOTAL } \\
\text { EXTRANJEROS }\end{array}$ & TOTAL \\
\hline Hombres & 57,8 & 52,6 & 48,6 & 33,5 & 48,6 & 47,2 & 56,2 \\
\hline Mujeres & 46,5 & 40,5 & 39,8 & 22,6 & 38,1 & 38,4 & 45,3 \\
\hline Total & 52,5 & 49,5 & 43,8 & 29,7 & 43,9 & 43,1 & 51,0 \\
\hline
\end{tabular}

Desde una perspectiva territorial, el comportamiento de autóctonos e inmigrantes no es exactamente el mismo (figura 4). Coinciden en la excepcionalidad de los lugares centrales, como es el caso de Barcelona (solo trabajan fuera el 21,8\% de los extranjeros y el 25,9\% de los autóctonos), aunque con algunos matices: entre los autóctonos, en Barcelona este porcentaje siempre es inferior al $40 \%$, cosa que no siempre ocurre entre los extranjeros, quienes además reproducen este efecto de centralidad en los centros de ciudades medias periféricas, como Terrassa, Sabadell y Sant Cugat del Vallès. La movilidad más alta, por encima del $70 \%$, se observa entre los autóctonos en ambos extremos de Barcelona y en municipios pequeños de la primera periferia metropolitana, así como en los colindantes con las ciudades de Sabadell y Granollers. Serían municipios donde primaría, en buena parte de ellos, la cuestión residencial por encima de la laboral. ${ }^{7}$ Esta pauta no se observa para los inmigrantes, entre los que tienen mayor fuerza la vecindad inmediata (es lo que sucede en las ciudades de la segunda corona metropolitana, como Martorell, Terrassa o Vilanova i la Geltrú) o la proximidad de las líneas ferroviarias en la comarca del Vallés Oriental (se podría reseguir este corredor uniendo los municipios con más del $70 \%$ de inmigrantes trabajando fuera que siguen una continuidad lineal a la derecha de la imagen).

En segundo lugar se analiza el tiempo entre lugar de residencia y de trabajo, ${ }^{8}$ bajo el criterio de considerar aquellos que invierten más de 45 minutos en sus desplazamientos. ${ }^{9}$ Esta es la situación del 22,5\% de los autóctonos, pero del 32,3\% de los inmigrantes. Además, afecta más a las mujeres que a los hombres. A excepción de los asiáticos, las mujeres emplean más tiempo en sus viajes cotidianos, siendo las africanas las que experimentan diferencias más acusadas (figura 5, izquierda). Geográficamente, entre los autóctonos, son los residentes en Barcelona los que conocen porcentajes menores; en cambio, es en los municipios de la segunda corona donde se incrementa esta proporción. Existe una clara excepción; el distrito barcelonés de Nou Barris, en el noreste de la ciudad. Este distrito, junto con Santa

Debido a su localización, se trata de municipios de hábitat disperso y caracterizados por altas proporciones de vivienda unifamiliar.

8 En este caso no se dispone de información para los que declaran trabajar en más de un municipio.

9 Se trata de 45 minutos por desplazamiento, dando lugar a un mínimo de más de hora y media de trayectos si se considera ida y vuelta. 
Coloma de Gramenet, identifican un polo de desventaja evidente, ${ }^{10}$ al emplazarse entre las zonas con mayor tiempo de desplazamiento entre los autóctonos, a pesar de formar parte de la ciudad central (Ajenjo \& Bayona, 2017). Tal situación se agrava entre los inmigrantes y se reproduce en las periferias de otras grandes urbes metropolitanas (Sabadell o Terrassa, por ejemplo).

FIgura 4 Proporción de ocupados que trabajan fuera del municipio de residencia según lugar de nacimiento, Región Metropolitana de Barcelona, 2011

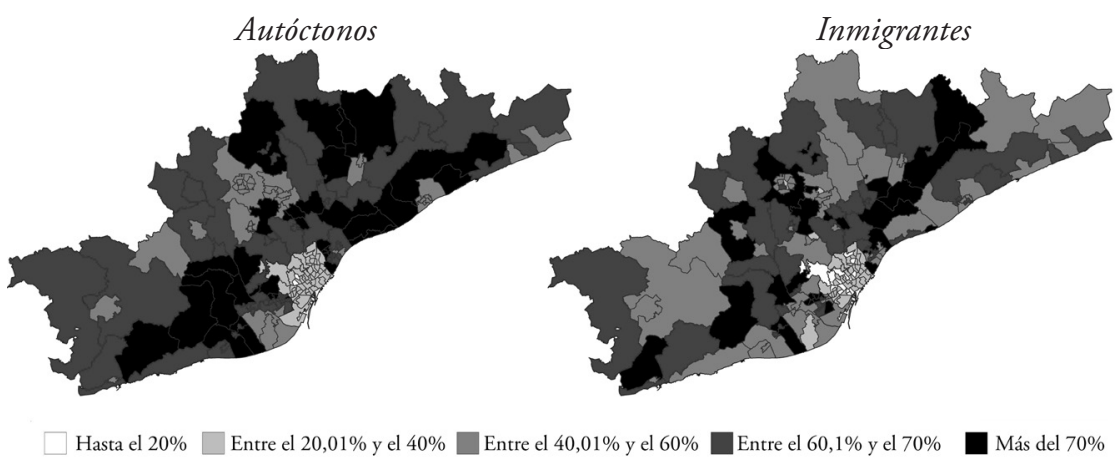

FUENTE ELABORACIÓN PROPIA A PARTIR DE LOS MICRODATOS DEL CENSO DE POBLACIÓN DE 2OI I, CON DATOS DEL INE

FIGURA 5 | Características de la movilidad de los ocupados que trabajan fuera del municipio de residencia por país de nacimiento, RMB, 2011

Tiempo de desplazamiento Utilización de vehiculo privado

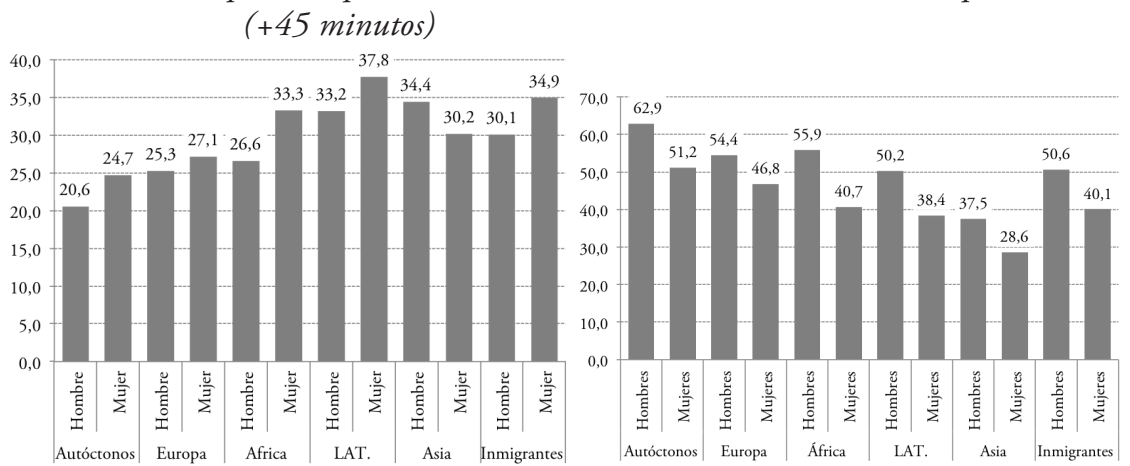

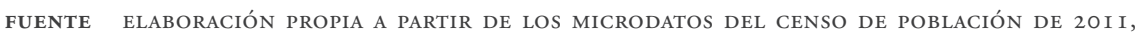
CON DATOS DEL INE

10 Se trataría de zonas situadas entre las de menor poder adquisitivo de toda la Región Metropolitana, identificando la penalización de las clases sociales más bajas. 
FIGURA 6 | Tiempo de desplazamiento (>45 minutos) y uso del vehículo privado, Región Metropolitana de Barcelona, 2011
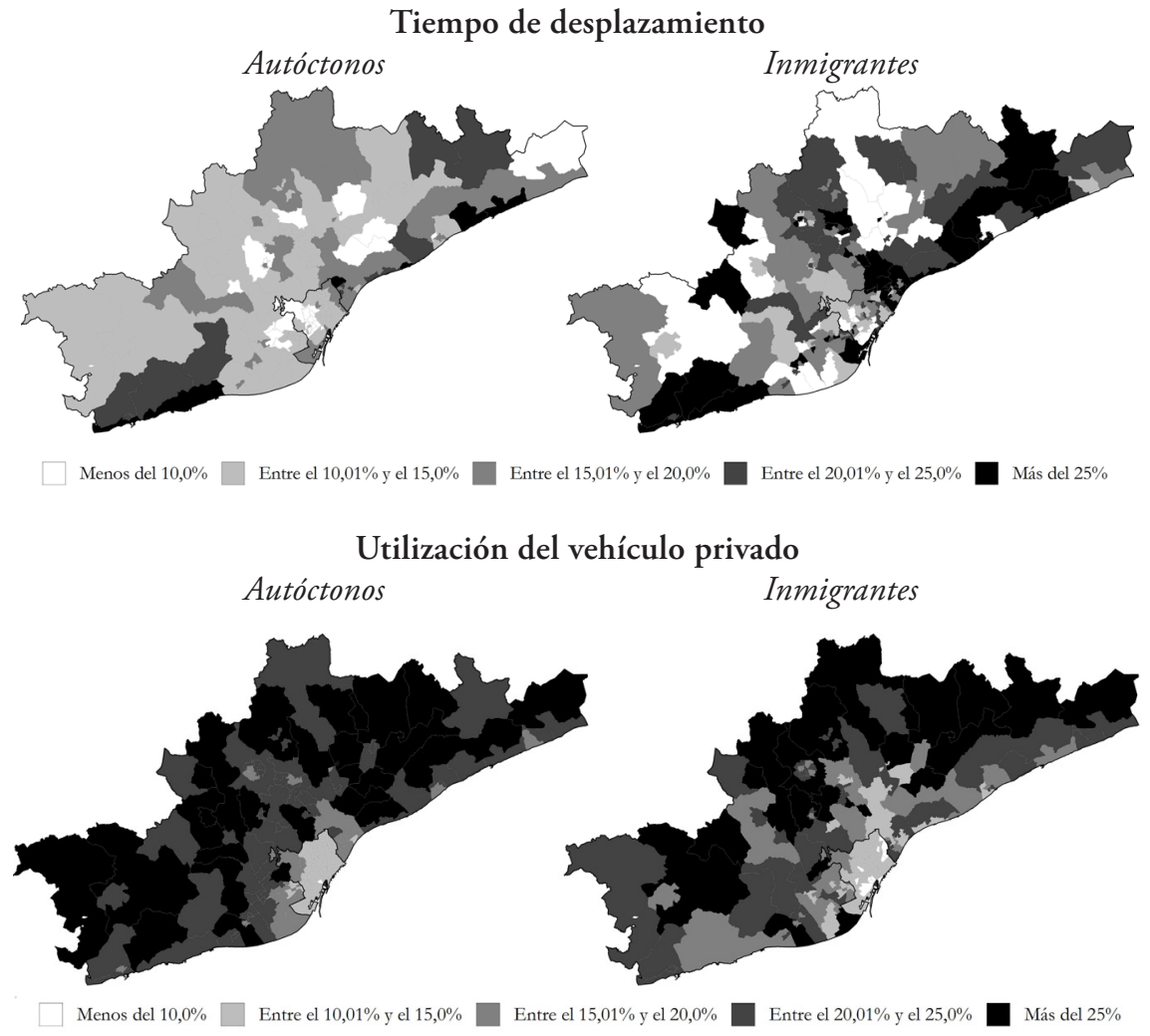

FUENTE ELABORACIÓN PROPIA A PARTIR DE LOS MICRODATOS DEL CENSO DE POBLACIÓN DE 20 I I, CON DATOS DEL INE

En último término, se considera la utilización del vehículo privado en la movilidad (figura 5, derecha). Se han dividido los diversos tipos de medios de transporte entre privados, públicos y otros medios (de la suma de caminando, utilizando bicicleta y un genérico "otros medios"). Los resultados indican cómo el vehículo privado es mayoritario entre los autóctonos (57,1\%), pero no entre los inmigrantes (45,5\%). De forma similar a la variable anterior, el comportamiento difiere según el sexo: las mujeres emplean mucho menos el vehículo privado $(62,9 \%$ en el caso de los hombres frente a $51,2 \%$ las mujeres, entre los autóctonos; $50,6 \%$ y 40,1\%, respectivamente, entre los inmigrantes). De los inmigrantes, son los africanos los que utilizan más el vehículo privado (52\%), mientras los asiáticos se encuentran en el extremo contrario $(34,5 \%)$, con grandes distancias entre sexos en el caso de los africanos $(55,9 \%$ para $40,7 \%)$. Por otro lado, cuando el vehículo de motor utilizado es un coche o furgoneta, no existen grandes diferencias entre autóctonos e inmigrantes en 
cuanto a si figuran como conductor o acompañante; en ambos casos, en alrededor del $14 \%$ de los casos aparecen como acompańantes, con pocas variaciones entre sexos. Únicamente las mujeres africanas $(22,8 \%)$ y los asiáticos, con independencia del sexo $(18,3 \%$ y $20,1 \%)$, presentan proporciones superiores. Desde una perspectiva territorial (figura 6), se observa claramente la situación diferenciada de los mayores centros urbanos, donde la movilidad en coche es menor. Esto es muy claro en Barcelona, pero también se observa en Terrassa, Sabadell, Granollers o Vilanova i la Geltrú, o de forma más clara en el centro de l'Hospitalet de Llobregat. Entre los inmigrantes, esta pauta se reproduce con mayor evidencia, y se disipa hacia lugares menos centrales. En la segunda corona, en cambio, los porcentajes apenas varían en relación con los autóctonos.

\section{Territorio y movilidad: ¿̨cuál es el efecto de la concentración residencial sobre la movilidad habitual?}

En la figura 7 se muestra, para cada uno de los cuatro principales colectivos analizados, el resultado de la regresión logística que compara los datos de la movilidad habitual (medido como el porcentaje de aquellos que se desplazan de municipio para trabajar) entre estos mismos extranjeros y los espańoles en función de la zona de residencia, definida esta última a partir de la concentración residencial de cada uno de los grupos. Los resultados se presentan como porcentajes de residentes que cambian de municipio por motivos laborales. Estos porcentajes han sido controlados a partir de una regresión logística introduciendo el sexo, la edad, el nivel de estudios y el sector de actividad como variables de control. Es decir, a igualdad de estas condiciones con los autóctonos, se observa el efecto de la concentración sobre la movilidad laboral (véase el apartado de metodología).

A pesar de que en los cuatro colectivos analizados la movilidad por motivos de trabajo es significativamente inferior a la movilidad de los autóctonos, la concentración de los inmigrantes no tiene, en todos ellos, el mismo efecto.

Para los europeos, la concentración tiene un peso significativo (p-valor $<0,001)$ en las diferencias de movilidad respecto de los autóctonos, y muestra un sentido unidireccional: a mayor concentración, menor movilidad y mayor diferencia con los autóctonos. En aquellos espacios de mayor concentración existen 15 puntos de diferencia entre la movilidad de uno y otros (49,7\% los autóctonos y 34,4\% los europeos inmigrantes), una diferencia que es apenas de 2 puntos en las zonas de no concentración.

En cambio, vivir en un entorno más o menos concentrado no comporta ninguna diferencia significativa entre los africanos ( $p$-valor=0,205), los cuales tienen un patrón de movilidad parecido (aunque siempre a un nivel inferior) a los autóctonos que conviven con ellos.

A pesar de que entre los latinoamericanos el efecto concentración vuelve a ser significativo ( $\mathrm{p}$-valor $<0,001$ ), su sentido es el opuesto al descrito para los europeos. Así, si en estos últimos la concentración va asociada a una mayor diferencia con los autóctonos, en el colectivo latinoamericano va asociada a una menor diferencia (si para los latinoamericanos que viven en zonas no concentradas o de bajo nivel 
de concentración la diferencia de movilidad con los autóctonos es de unos seis puntos porcentuales, para los que viven en zonas de mayor concentración las diferencias desaparecen por completo). En este caso, existe un aumento de la movilidad en los espacios de mayor concentración, situación que responde a su localización. Debemos tener en cuenta que seis de las siete zonas de mayor concentración se encuentran situadas en el eje formado por l'Hospitalet de Llobregat, Esplugues de Llobregat y Cornellà de Llobregat, al oeste de la ciudad condal. Se trata de una zona limítrofe a Barcelona donde buena parte de sus vecinos se trasladan para trabajar, en su mayoría hacia Barcelona (en este caso, el porcentaje de ocupados latinoamericanos que trabajan en el municipio de Barcelona es similar al de los autóctonos).

FIgURA 7 Proporción de ocupados que trabajan fuera del municipio según la concentración de cada agrupación continental, 2011
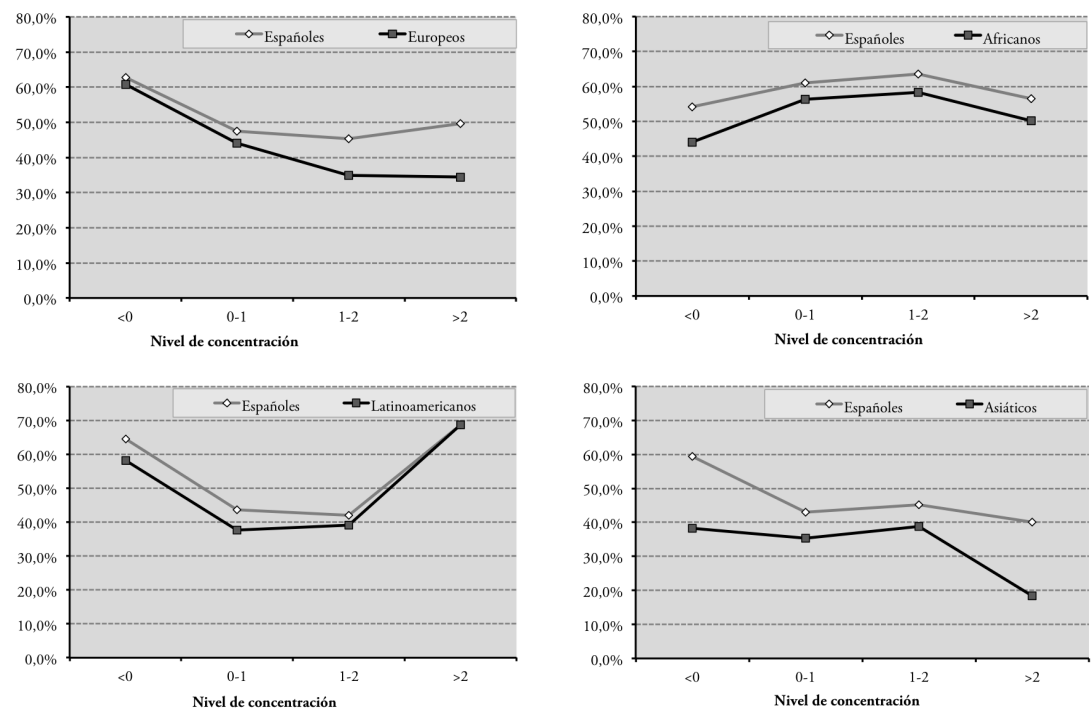

FUENTE ELABORACIÓN PROPIA CON BASE EN MICRODATOS DEL CENSO DE POBLACIÓN DE 20 I I

En último lugar, entre los asiáticos vuelve a ser significativo el efecto de la concentración ( $\mathrm{p}$-valor $<0,001)$. La mayor concentración coincide con la menor movilidad (por debajo del 20\%) y con una importante diferencia con los autóctonos. El barrio del Raval (dividido en dos unidades), más una zona de Badalona (alrededor del barrio de Sant Roc), son las tres zonas de máxima concentración, donde apenas existe movilidad laboral hacia otros municipios y donde, en todo caso, ella es significativamente menor que la de los autóctonos que residen en estas mismas zonas.

Resumiendo, en tres de los cuatro casos (a excepción de los africanos), el efecto de la concentración sobre la movilidad por motivos de trabajo es significativo. En dos de ellos (europeos y asiáticos), la máxima concentración coincide con la mínima movilidad, mientras que entre los latinoamericanos ocurre exactamente lo contrario. Esto nos hace pensar en el efecto que tiene sobre la movilidad el lugar 
donde se produce la concentración: no es lo mismo encontrarse concentrado en el Raval, en el centro de Barcelona, que en l'Hospitalet de Llobregat, en la primera periferia. Además de este efecto locacional, no todos los grupos de inmigrantes experimentan de la misma manera la concentración. El caso de los asiáticos sería el paradigmático, ya que la concentración, sumada a la existencia de numerosos negocios étnicos, puede originar sus bajos niveles de movilidad.

\section{Conclusiones}

La llegada de miles de inmigrantes extranjeros a la Región Metropolitana de Barcelona ha representado el mayor cambio reciente en el mercado laboral metropolitano, con una población activa cada vez con más presencia de mujeres y de inmigrantes. Conjuntamente con los procesos de dispersión residencial y de la actividad económica, dibujan un nuevo panorama que justifica el estudio aquí realizado.

La actividad de los inmigrantes extranjeros se caracteriza por su mayor precariedad, en parte debido al impacto de la crisis económica. Esta situación aparece claramente en el estudio de las condiciones de movilidad diaria que experimentan, especialmente si se hace referencia a dos de sus componentes: el tiempo empleado y el medio de transporte (público o privado). Esto es consecuencia de sus condiciones residenciales, pero también de las características de sus empleos. Mayor tiempo de desplazamiento y mayor utilización del transporte público en comparación con el privado son dos de las principales características, coincidiendo con lo que la literatura sobre el tema apunta para los colectivos más vulnerables (Avellaneda, 2008). Al mismo tiempo, se produce una menor predisposición a trabajar fuera de su propio municipio, que afecta en mayor medida a las mujeres inmigrantes, especialmente a las asiáticas. Esto último contradice las visiones sobre población vulnerable y movilidad (Rodríguez, 2008), ya que no se estaría produciendo una mayor movilidad entre la población inmigrante, lo que refuerza la necesidad de estudios específicos para este colectivo. Los resultados aquí obtenidos apuntan a mostrar de qué forma, entre la población inmigrante y en particular aquella de llegada reciente, como es el caso de la asentada en la RMB, el lugar de residencia y el de trabajo mostrarían una elevada interrelación, con el corolario, en condiciones similares, de una menor probabilidad de desplazarse. En cuanto a la perspectiva de género, las diferencias en la movilidad habitual observadas entre hombres y mujeres autóctonos se mantienen, e incluso se acrecientan entre los inmigrantes, donde se observa una brecha mayor y desfavorable a las mujeres. Esto último refuerza el discurso de las desigualdades de género entre la población inmigrante, y el desigual efecto de la concentración para las mujeres de algunos colectivos, como el asiático.

Por otro lado, y tal y como se planteaba en la hipótesis de trabajo, la concentración residencial tiene efecto sobre las pautas de movilidad. Ahora bien, al contrario de lo que pensábamos en un inicio, dicho efecto es dual y se refuerza a partir de la localización de la concentración. Por un lado, el efecto es significativo solo en tres de los cuatro casos estudiados (la excepción la representan los africanos), y su existencia depende de dónde se produce la localización de la concentración. Si esta ocurre en las zonas centrales, se relaciona con una menor movilidad. En tal 
caso, el comportamiento de los inmigrantes residentes difiere del que muestra el resto de convecinos, siendo la existencia de negocios étnicos y unas fuertes redes de contactos los factores que explicarían tales resultados en barrios del centro de la ciudad con elevadas proporciones de inmigrantes. Tal sería el caso de los asiáticos, mientras que este mismo efecto entre los europeos se debería explicar por otras razones. $\mathrm{Si}$, en cambio, la concentración se produce en la primera periferia, como entre los latinoamericanos, existe una mayor movilidad, al contrario de lo esperado. Si bien es una movilidad similar a la del resto de los vecinos con las mismas características, las otras variables estudiadas denotan la mayor vulnerabilidad de los inmigrantes en comparación con el conjunto de población de estos mismos espacios. Por otro lado, debemos considerar cómo, con independencia del grado de segregación mostrado por unos u otros colectivos, los factores que tienen una mayor relación con las características de la movilidad son la concentración y dónde esta se produce.

Más allá del efecto concentración, los descriptivos muestran diferencias entre la movilidad de autóctonos y la de inmigrantes. Primero, se observa cómo el efecto centralidad de las grandes ciudades se produce con mayor peso entre los inmigrantes, no solo en Barcelona, sino también en las ciudades intermedias. En cambio, los municipios conurbados a la ciudad central son lugares de residencia, pero no siempre de trabajo, y es esta última situación lo que los hace diferentes de los autóctonos en la movilidad. En ambos casos se refuerza la excepcionalidad urbana, mientras que las periferias castigan, de forma clara, la movilidad.

Finalmente, recalcar cómo la mayor ocupabilidad de las mujeres inmigrantes, especialmente las latinoamericanas, se produce a pesar de su peor relación con la movilidad. En este caso, la existencia de unos tiempos de viaje elevados no significa la no aceptación de estos lugares de trabajo. Las mayores cuotas de ocupación se consiguen con un alto grado de penalización, que se relaciona directamente con el lugar de residencia. Lo que para unos sería visto como signo de "resiliencia" no es más que un reflejo de la crisis y de su mayor vulnerabilidad, tanto como mujeres que en cuanto inmigrantes.

\section{Referencias bibliográficas}

Ajenjo, M. (2005). Evolució i caracteristiques de la mobilitat habitual per treball a Catalunya (1986-2011). L'accessibilitat com a variable intermèdia. Tesis doctoral Ciències Socials. Departament de Geografia, Universitat Autònoma de Barcelona.

Ajenjo, M. \& Bayona, J. (2017). Movilidad de la población e inmigración extranjera en el área metropolitana de la ciudad de Barcelona. Anales de Geografia de la Universidad Complutense de Madrid, 37(1), 11-41. http://revistas.ucm.es/index.php/AGUC/ article/view/55954

Alba, R. D., Logan, J. R., Stults, B. J., Marzan, G. \& Zhang, W. (1999). Immigrant groups in the suburbs: A Reexamination of suburbanization and Spatial Assimilation. American Sociological Review, 64(3), 446-460. http://dx.doi.org/10.2307/2657495

Alberich, J. (2010). L'ús de l'espai. Papers RMB (Regió Metropolitana de Barcelona), 51, 28-43. 
Avellaneda, P. (2008). Movilidad cotidiana, pobreza y exclusion social en la ciudad de Lima. Anales de Geografia de la Universidad Complutense, 28(2), 9-35. http://revistas.ucm.es/ index.php/AGUC/article/view/31965

Bayona, J. \& López-Gay, A. (2011). Concentración, segregación y movilidad residencial de los extranjeros en Barcelona. Documents d'Anàlisi Geogràfica, 57(3), 381-412. http:// diposit.ub.edu/dspace/bitstream/2445/22643/1/588400.pdf

Bayona, J. \& Pujadas, I. (2014). Movilidad residencial y redistribución de la población metropolitana: los casos de Madrid y Barcelona. EURE, 40(119), 261-287. http:// dx.doi.org/10.4067/S0250-71612014000100012

Blázquez, M.Llano, C. \& Moral, J. (2010). Commuting times: Is thereany penalty for immigrants? Urban Studies, 47(8), 1663-1686. http://dx.doi.org/10.1177/0042098009356127

Cebollada, À. (2009). Mobility and labour market exclusion in the Barcelona Metropolitan Region. Journal of Transport Geography, 17(3), 226-233. https://doi.org/10.1016/j. jtrangeo.2008.07.009

Courgeau, D. (1988). Méthodes de mesure de la mobilité spatiale. Migrations internes, mobilité temporaire, navettes. París: Institut National d'Études Démographiques.

Duncan, O. D. \& Duncan, B. (1955). A methodological analysis of segregation indexes. American Sociological Review, 20(2), 210-217. http://dx.doi.org/10.2307/2088328

Ellis, M., Wright, R. \& Parks, V. (2004). Work together, live apart? Geographies of racial and ethnic segregation at home and at work. Annals of the Association of American Geographers, 94(3), 620-637. http://dx.doi.org/10.1111/j.1467-8306.2004.00417.x

Esteban, J. (2003). La Regió Metropolitana de Barcelona. Papers rmb (Regió Metropolitana de Barcelona), 39, 31-41. http://www.raco.cat/index.php/PapersIERMB/article/ view/103918

Galeano, J., Sabater, A. \& Domingo, A. (2014). Formació i evolució dels enclavaments ètnics a Catalunya abans i durant la crisi econòmica. Documents d'Anàlisi Geogràfica, 60(2), 261-288. https://doi.org/10.5565/rev/dag.111

Galeano, J. \& Bayona, J. (2015). Assentament territorial de la població estrangera a l’Àrea Metropolitana de Barcelona en el segle xxi. En A. Domingo (coord.), Recerca $i$ immigració VII: Migracions del segle xx $i$ xxi a Catalunya. Una mirada Candeliana (pp. 95-121). Col-lecció Ciutadania i immigració no. 11. Barcelona: Generalitat de Catalunya, Departament de Benestar Social i Família. https://ddd.uab.cat/pub/ llibres/2015/167765/recerca_immigracioVII_a2015.pdf

García-Almirall, P., Fullaondo, A. \& Frizzera, A. (2008). Inmigración y espacio socioresidencial en la Región Metropolitana de Barcelona. Ciudad y Territorio. Estudios Territoriales, 40(158), 727-744. http://www-cpsv.upc.es/inmigracionviviendaciudad/ docs/13_CyTET-158-06.pdf

García Palomares, J. C. \& Gutiérrez Puebla, J. (2007). Pautas de movilidad en el área metropolitana de Madrid. Cuadernos de Geografía, (81-82), 7-30. https://www.uv.es/ cuadernosgeo/CG81_82_007_030.pdf

Glitz, A. (2014). Ethnic segregation in Germany. Labour Economics, 29, 28-40. https://doi. org/10.1016/j.labeco.2014.04.012

Gorard, S. \& Taylor, C. (2002). What is segregation? A comparison of measures in terms of 'strong' and 'weak' compositional invariance. Sociology, 36(4), 875-895. https://doi. org//10.1177/003803850203600405 
Gramberg, P. (1998). School segregation: The case of Amsterdam. Urban Studies, 35(3), $547-$ 564. https://doi.org//10.1080/0042098984907

Gutiérrez Puebla, J. \& García Palomares, J. C. (2005). Cambios en la movilidad en el area metropolitana de Madrid: el creciente uso del transporte privado. Anales de Geografia, (25), 331-351. http://revistas.ucm.es/index.php/AGUC/article/view/ AGUC0505110331A

Johnston, R., Forrest, J. \& Poulsen, M. (2002). Are there ethnic enclaves/ghettos in English cities? Urban Studies, 39(4), 591-618. https://doi.org//10.1080/00420980220119480

Marcińczak, S., Tammaru, T., Strömgren, M. \& Lindgren, U. (2015). Changing patterns of residential and workplace segregation in the Stockholm metropolitan area. Urban Geography, 36(7), 969-992. http://dx.doi.org/10.1080/02723638.2015.1012364

Marmolejo, C. \& Roca Cladera, J. (2008). La localización intrametropolitana de las actividades de la información: un análisis para la Región Metropolitana de Barcelona 1991-2001. Scripta Nova. Revista Electrónica de Geografía y Ciencias Sociales, 12(268). http://www. ub.edu/geocrit/sn/sn-268.htm

Marquet, O. \& Miralles-Guash, C. (2017). Resilient territories and mobility adaptation strategies in time of economic recession: Evidence from the metropolitan region of Barcelona, Spain 2004-2012. European Urban and Regional Studies. http://dx.doi. org/10.1177/0969776417703158.

Martori, J.C. \& Apparicio, P. (2011). Changes in spatial patterns of the immigrant population of a Southern European metropolis: the case of the Barcelona Metropolitan Area (2001-2008). Tijdschrift voor Economische en Sociale Geografie, 102(5), 562-581. http://dx.doi.org/10.1111/j.1467-9663.2011.00658.x

Mendizàbal, E. (1991). Les noves tendències del poblament. En Societat Catalana de Geografia (eds.), Actes del Primer Congrés Català de Geografia. Vol. II: Ponències (pp. 159-178). Barcelona.

Miralles-Guash, C. (2011). Dinámicas metropolitanas y tiempos de la movilidad. La Región Metropolitana de Barcelona como ejemplo. Anales de Geografía de la UCM, 31(1), 125145. http://dx.doi.org/10.5209/rev_AGUC.2011.v31.n1.6

Moreras, J. (2002). Les activitats comercials dels residents estrangers a Ciutat Vella. Barcelona: Fundació сіров (Barcelona Centre for International Affairs).

Newbold, K. B., Scott, D. M. \& Burke, C. (2015). Immigrant status and commute distance: an exploratory study based on the greater Golden Horseshoe. Trasportation, 44(1), 181-198. http://dx.doi.org/10.1007/s11116-015-9633-y

Painter, G., Liu, C.Y. \& Duan, Z. (2007). Immigrants and the spatial mismatch hypothesis: Employment outcomes among immigrant youth in Los Angeles. Urban Studies, 44(13), 2627-2649. https://doi.org/10.1080/00420980701558368

Pujadas, I. (2009). Movilidad residencial y expansión urbana en la Región Metropolitana de Barcelona, 1982-2005. Scripta Nova. Revista Electrónica de Geografia y Ciencias socials, 13(290). http://www.ub.edu/geocrit/sn/sn-290.htm

Rodríguez Vignoli, J. (2008). Movilidad cotidiana, desigualdad social y segregación residencial en cuatro metropolis de América Latina. EURE, 34(103), 49-71. http://dx.doi. org/10.4067/S0250-71612008000300003 
Rubiales, M., Bayona, J. \& Pujadas, I. (2012). Patrones espaciales de la segregación residencial en la Región Metropolitana de Barcelona: Pautas de segregación de los grupos altos. Scripta Nova, Revista Electrónica de Geografía y Ciencias Sociales, 16(423). http://www. ub.edu/geocrit/sn/sn-423.htm

Sabater, A. \& Galeano, J. (2015). The nexus between occupational and residential segregation. En A. Domingo, A. Sabater \& R. Verdugo (eds.), Demographic analysis of Latin American immigrants in Spain (pp. 105-132). Applied Demography Series 5. Dordrecht, Heidelberg, Londres, Nueva York: Springer.

Sabater, A., Bayona, J. \& Domingo, A. (2012). Internal migration and residential patterns across Spain after unprecedented international migration. En N. Finney \& G. Catney (eds.), Minority internal migration in Europe (Cap. XIv, pp. 293-311). International Population Studies Series. Surrey: Ashgate Publishing.

Schindler, B. (2007). Living and learning separately? Ethnic segregation of school children in Copenhagen. Urban Studies, 44(7), 1329-1354.

Strömgren, M., Tammaru, T., Danzer, A. M., van Ham, M. Marcinczak, S., Stjernström, O. \& Lindgren, U. (2014). Factors shaping workplace segregation between natives and immigrants. Demography, (51), 645-671. https://doi.org/10.1007/s13524-013-0271-8

Tammaru, T., Strömgren, M., van Ham, M. \& Danzer, A. (2015). Gender differences in the effect of residential segregation on workplace segregation among newly arrived immigrants. IZA Discussion Paper, 8932. http://ftp.iza.org/dp8932.pdf

van Ham, M., Manley, D., Bailey, N., Simpson, L. \& Maclennan, D. (eds.) (2012). Neighbourhood effects research: new perspectives. Dordrecht, Heidelberg, Londres, Nueva York: Springer. https://doi.org/10.1007/978-94-007-2309-2_1

Vono, D. \& Vidal, E. (2012). The impact of informal networks on labour mobility: Immigrant's first job in Spain. Migration Letters, 9(3), 237-247. http://www.tplondon.com/journal/ index.php/ml/issue/view/37

Yang-Liu, C. (2009). Ethnic enclave residence, employment, and commuting of Latino workers. Journal of Policy Analysis and Management, 28(4), 600-625. https://doi. org/10.1002/pam.20457 


\section{Anexo}

FIgURA A I Principales municipios de la Región Metropolitana de Barcelona

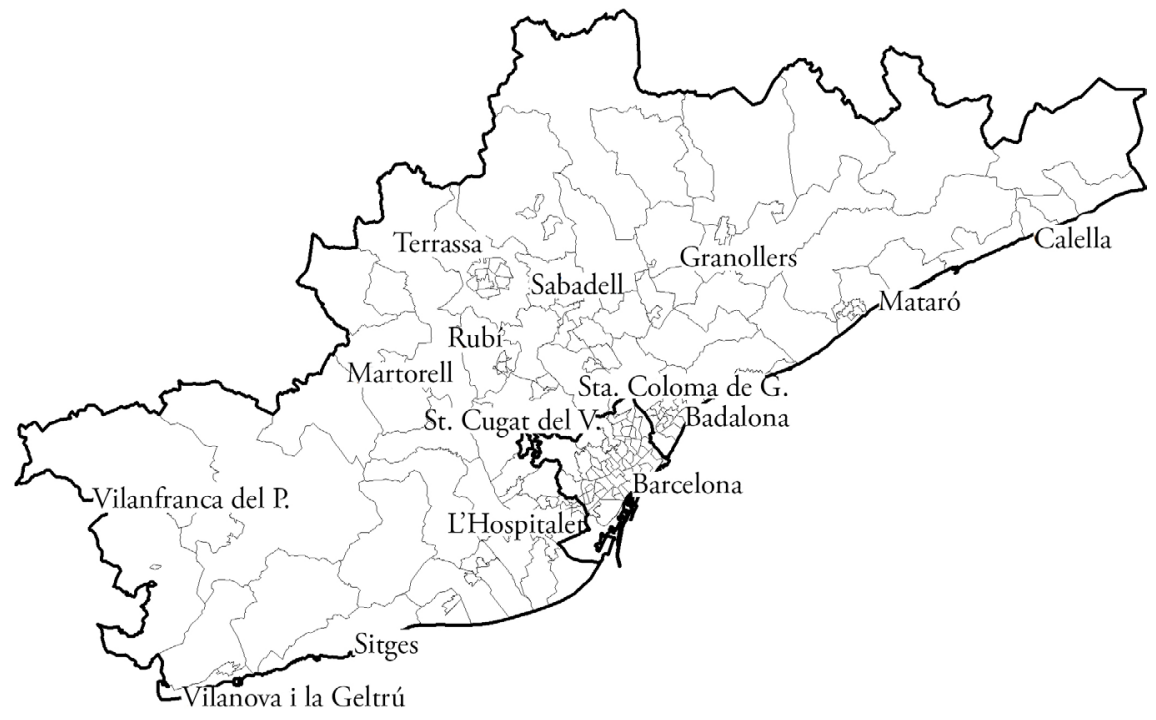

FUENTE ELABORACIÓN PROPIA 